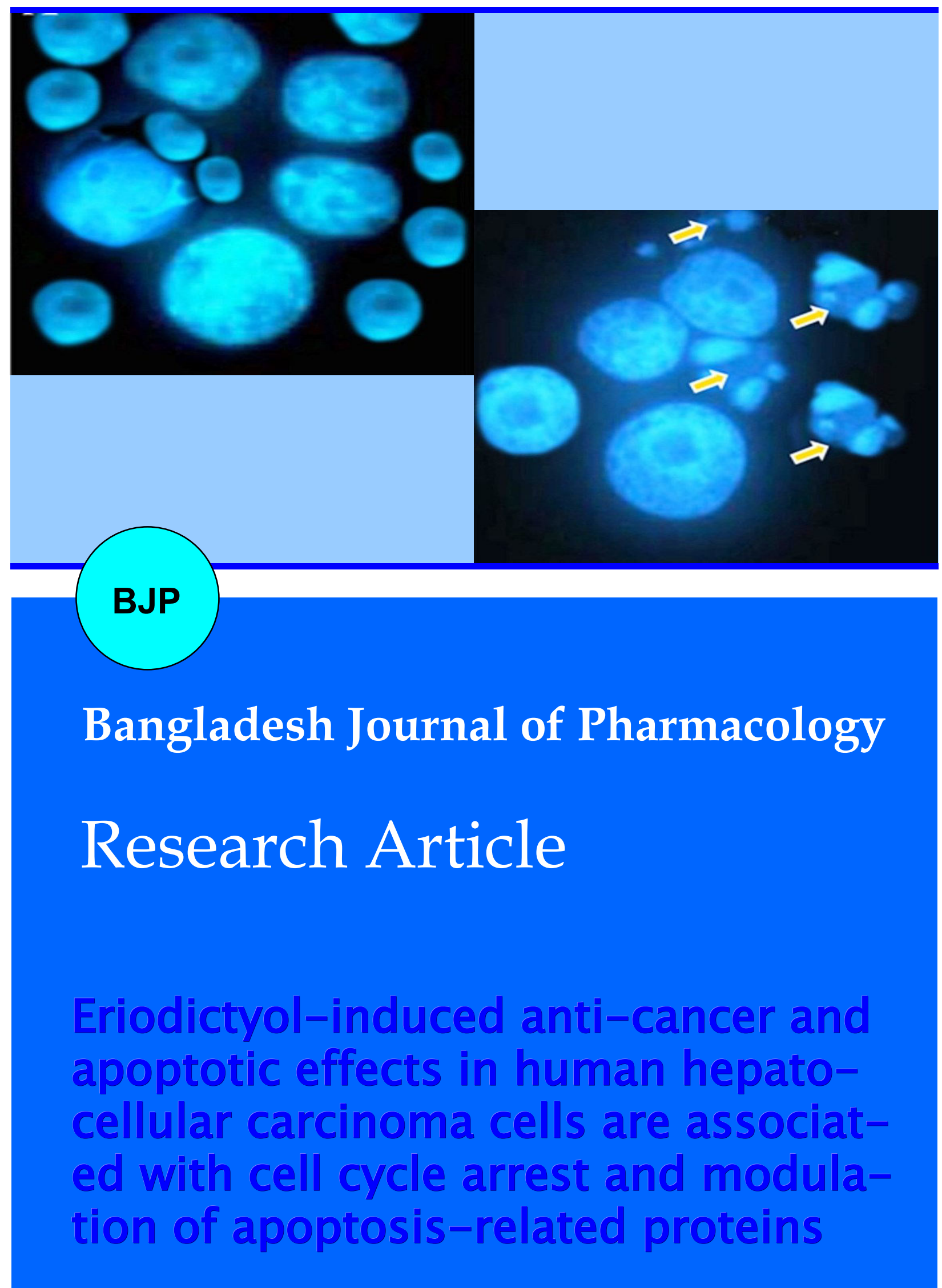


Abstracted/indexed in Academic Search Complete, Asia Journals Online, Bangladesh Journals Online, Biological Abstracts, BIOSIS Previews, CAB

Abstracts, Current Abstracts, Directory of Open Access Journals, EMBASE/Excerpta Medica, Google Scholar, HINARI (WHO), International

\title{
Eriodictyol-induced anti-cancer and apoptotic effects in human hepatocellular carcinoma cells are associated with cell cycle arrest and modulation of apoptosis-related proteins
}

\author{
Fang Wang1, Yu-Hang Wang', Jing-Jing Wang', He-Lin $\mathrm{Xu}^{2}$ and Chang-Miao Wang² \\ ${ }^{1}$ Department of Healthy Portion and ${ }^{2}$ General Surgery, First Affiliated Hospital of Dalian Medical University, Dalian, \\ Liaoning 116011 , China.
}

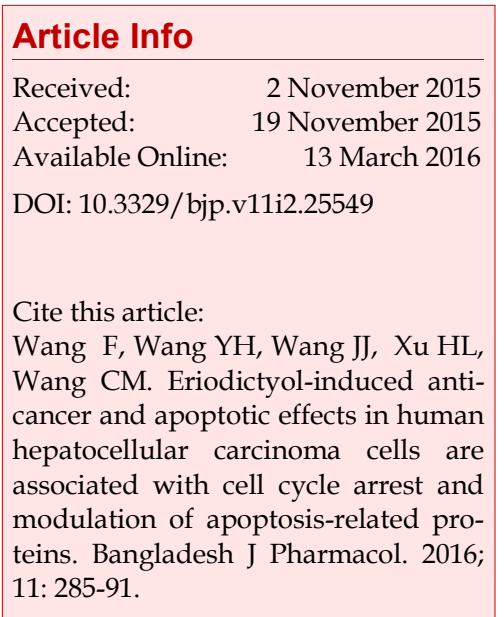

\begin{abstract}
The objective of the present study was to investigate the anti-cancer effects of eriodictyol in human hepatocellular carcinoma cells (Hep-G2) and normal liver hepatocyte cell line (AML12) along with evaluating its mode of action. Sulforhodamine B assay was used to evaluate the cytotoxic effect of the compound while as fluorescence microscopy was involved to demonstrate the effect of eriodictyol on cellular apoptosis. Flow cytometry was used to investigate the effect of eriodictyol on cell cycle while Western blot analysis revealed the effect on apoptosis-related protein expressions. Results indicate that eriodictyol-induced selective and concentration-dependent cytotoxic effect on Hep-G2 cancer cells while AML12 normal liver cells were very less susceptible to its effect. Eriodictyol-induced apoptosis related morphological changes including chromatin condensation and nuclear fragmentation. It also induced G2/M cell cycle arrest in these cells. Eriodictyol led to up-regulation of Bax and PARP and down-regulation of Bcl-2 protein.
\end{abstract}

\section{Introduction}

Hepatocellular cancer was the second most common cause of death during 2009-2010 throughout the world. It is a serious health problem, being the sixth most common cancer throughout the world (Jemal et al., 2011). Most cases of hepatocellular cancer are secondary to either a viral hepatitis infection (hepatitis B or C) or cirrhosis. Hepatocellular cancer has a 5-year natural mortality rate of more than $90 \%$, and it affects more than 500,000 people in the world per year, more than $50 \%$ of whom are in China (Amin et al., 2011). Dysregulation of the balance between proliferation and cell death represents a pro-tumorigenic principle in human hepatocarcinogenesis (Fabregat, 2009). The treatment options for hepatocellular cancer include chemotherapy, surgical resection and radiotherapy. One of the most effective treatment options for hepatocarcinoma includes liver transplantation. However, due to less availability of organs limits its application to many patients. Additionally, multidrug resistance and high risk of tumor recurrence further complicates the treatment regimens for hepatocellular cancer (Amin et al., 2011; Tabone and Pellicano, 2006). Therefore, there is an urgent need for more effective, novel and less toxic anticancer agents against liver cancer including natural products and their synthetic or semisynthetic derivatives.

Eriodictyol (Figure 1) is a naturally occurring flavanone extracted from many plants including Eriodictyon californicum, Millettia duchesnei, Eupatorium arnottianum and Rosa canina. There are lots of reports which claim that natural flavonoids and flavanones exhibit a widespectrum of biological activities including antimicrobial, anti-inflammatory and anti-cancer activities (Ley et al., 2005; Ngandeu et al., 2008; Clavin et al., 2007; Havsteen, 1983). The anti-cancer and apoptotic activi- 
ties of eriodictyol against Hep-G2 hepatocellular carcinoma cells has not been reported so far. So, the aim of the present investigation was to evaluate the anticancer and apop-totic activities of eriodictyol against Hep-G2 liver cancer cells and assess its mode of anticancer action.

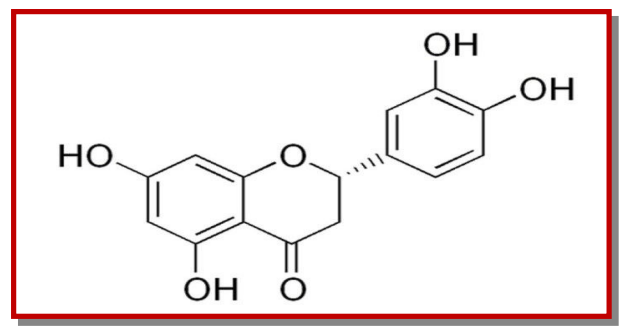

Figure 1: Chemical structure of eriodictyol

\section{Materials and Methods}

\section{Chemicals and other reagents}

Eriodictyol (purity $>95 \%$ ) was purchased from Sigma Chemical Company (USA), and $100 \mathrm{mg} / \mathrm{mL}$ solution dissolved in DMSO was stored at $-20^{\circ} \mathrm{C}$ prior to use. 3[4, 5-dimeth-yl-2-thiazolyl]-2, 5-diphenyl tetrazolium bromide (MTT) was purchased from Molecular Probes (USA). RPMI, fetal bovine serum, penicillin-streptomycin were obtained from Life Technologies (USA). Primary antibodies against caspase-3, cytochrome c, Bax, Bcl-2, PARP-1, $\beta$-actin, and secondary antibodies (goat-anti-rabbit or goat-anti-mouse) were purchased from Pierce (USA).

\section{Box 1: Cell cycle analysis by flow cytometer \\ Principle}

The amount of nucleic acid dye (propidium iodide) incorporated is proportional to the amount of DNA. The stained material is then measured in the flow cytometer and the emitted fluorescent signal yields an electronic pulse with a height (amplitude) proportional to the total fluorescence emission from the cell.

\section{Requirements}

Cells (Hep-G2), 6-well plate, eriodictyol, phosphate buffer solution, ice-cold $70 \%$ ethanol, $-20^{\circ} \mathrm{C}$ freeze, incubator. propidium iodide, RNase A, FACS Calibur flow cytometer (Becton, Dickinson and Company, USA), eppendorf micropipette with microtips.

\section{Procedure}

Step 1: Step Hep-G2 cells $\left(2 \times 10^{6}\right.$ cells $\left./ \mathrm{mL}\right)$ were seeded into each well of 6 -well plates and incubated at $37^{\circ} \mathrm{C}$ for 24 hours for cell adhesion

Step 2: The cells were treated with different concentrations ( 0 , 10,50 and $100 \mu \mathrm{M}$ ) of eriodictyol for 48 hours

\section{Cell line and culture conditions}

Hep-G2 human liver cancer cell line was purchased from the Shanghai Institute of Cell Resource Center of Life Science (China) while as AML12 normal liver hepatocyte cell line was procured from American Type Culture Collection (USA). The cells were cultured in DMEM medium supplemented with $10 \%$ fetal bovine serum, $100 \mu \mathrm{g} / \mathrm{mL}$ streptomycin, and $100 \mathrm{U} / \mathrm{mL}$ penicillin maintained at $37^{\circ} \mathrm{C}$ in a humidified atmosphere with $5 \% \mathrm{CO}_{2}$.

\section{Cell viability assay using sulforhodamine B}

The cytotoxic effects of eriodictyol on the proliferation of Hep-G2 human liver cancer cells and AML12 normal liver cell line were evaluated by sulforhodamine B cell viability assay.

The cells $\left(2 \times 10^{5}\right.$ cells/well) were seeded in 96-well plates for 12 hours followed by treatment with different dosages of eriodictyol $(0,5,10,25,50$ and $100 \mu \mathrm{M})$ for 24 hours. Subsequently, the cells were fixed with $100 \mu \mathrm{L}$ of $0.5 \%$ trichloroacetic acid, washed with water and then stained with sulforhodamine B $(30 \mu \mathrm{L})$ dissolved in $2.5 \%$ acetic acid. The sulforhodamine B bound to cells was solubilized with $100 \mu \mathrm{L}$ of $5 \mathrm{mM}$ Tris base and then the absorbance was observed at $570 \mathrm{~nm}$.

\section{Fluorescence microscopy assay using DAPI staining}

Hep-G2 cells $\left(2 \times 10^{5}\right.$ cells $\left./ \mathrm{mL}\right)$ were taken in a petri dish and treated with $0,10,50$ and $100 \mu \mathrm{M}$ of eriodictyol for 48 hours. Subsequent to drug treatment, the

Step 3: After incubation, the cells were harvested and fixed with ice-cold $70 \%$ ethanol $(5 \mathrm{~mL})$ at $-20^{\circ} \mathrm{C}$ for 1 hour

Step 4: Before analysis, the cells were washed with cold phosphate buffer solution and re-suspended in $400 \mu \mathrm{L}$ of phosphate buffer solution, $50 \mu \mathrm{L}$ propidium iodide and $50 \mu \mathrm{L}$ RNase A

Step 5: The DNA contents were recorded by FACSCalibur flow cytometer equipped with Cell Quest software

\section{Precaution}

1. The number of cells used are critical. Samples should be analyzed at rates below 1,000 cells per second to get a good signal of discrimination between singlets or doublets

2. Staining procedure and analysis that require careful attention in order to avoid false interpretations

3. RNA would interfere in the staining, the solution should contain RNAase

4. Non-specific low level staining should be excluded. Only strongly stained cells should be collected

5. Exclude cell debris and aggregates. These will interfere with the measurement 
cells were washed with phosphate buffer solution twice, and then stained with DAPI $(10 \mu \mathrm{g} / \mathrm{mL}$ in phosphate buffer solution) for $50 \mathrm{~min}$ at $37^{\circ} \mathrm{C} .40 \mu \mathrm{L}$ of the cell suspension was put on a slide and images were taken using a fluorescence microscope (magnification, 400x; Olympus IX 81, Japan).

\section{Western blot analysis}

Hep-G2 cells were treated with $0,10,50$ and $100 \mu \mathrm{M}$ concentration of eriodictyol and then incubated for 48 hours. The adherent and floating cells were harvested and then washed three times with phosphate buffer solution and then lysed in RIPA buffer and protease inhibitor for $20 \mathrm{~min}$. The protein lysates (20 $\mu \mathrm{g} /$ lane) were separated by $10 \%$ SDS-PAGE and blotted onto nitrocellulose membranes. Each membrane was blocked with 5\% skim milk, and incubated with the selected primary anti-bodies against Bcl-2, PARP, cytochrome $c$, and $\beta$-actin overnight at $4^{\circ} \mathrm{C}$. Afterwards, the membrane was incu-bated with the secondary antibodies for 1 hour at room temperature and the formed complex was detected by Western blotting detection reagents (Trans Gene, China).

\section{Statistical analysis}

All data were derived from at least three independent experiments. The results were expressed as mean \pm SD. Differences between groups were analyzed using the Student's t-test. $\mathrm{p}<0.05$ was considered statistically significant.

\section{Results}

\section{Antiproliferative activity}

Eriodictyol led to a significant and concentration- dependent growth inhibition of liver cancer cells with $\mathrm{IC}_{50}$ value of $37.6 \mu \mathrm{M}$ (Figure 2). Figure 3 shows the cytotoxic effect of eriodictyol against AML12 normal liver hepatocyte cells which reveals that the compound showed very less cytotoxicity against normal cells indicating that eriodictyol is a selective cytotoxic agent against cancer cells. Such compounds are very promising for the anticancer drug discovery process, since most of the currently used anticancer drugs kill normal cells also in addition to killing cancerous cells.

\section{Fluorescence microscopic study of apoptosis-related cell morphological changes}

The apoptosis inducing effect of eriodictyol was further assessed by DAPI staining using fluorescence microscopy. Following the treatment with different doses of eriodictyol $(0,10,50$ and $100 \mu \mathrm{M})$ for 48 hours, the cells were analyzed by fluorescence microscope. Eriodictyol-treated cells stained with DAPI revealed chromatin condensation, fragmented nuclei and nuclear shrinkage which increased with the increasing dose of the compound (Figure 4A-D). The untreated cells showed normal nuclear structure with no signs of apoptosis.

\section{Eriodictyol induced G2/M cell cycle arrest}

Next it was assumed that eriodictyol would also target cell cycle phase distribution in Hep-G2 cells and carried out experiments in order to evaluate the effect of this compound on cell cycle distribution. The results which are depicted in Figure 5 and Figure 6 indicate that eriodictyol induces G2/M cell cycle arrest in a dosedependent manner. The percentage of cells in G2/M phase of the cell cycle increased from $12.3 \%$ in untreated control cells to $16.7 \%, 25.2 \%$ and $54.6 \%$ in 10 , 50 and $100 \mu \mathrm{M}$-eriodictyol treated cells respectively.

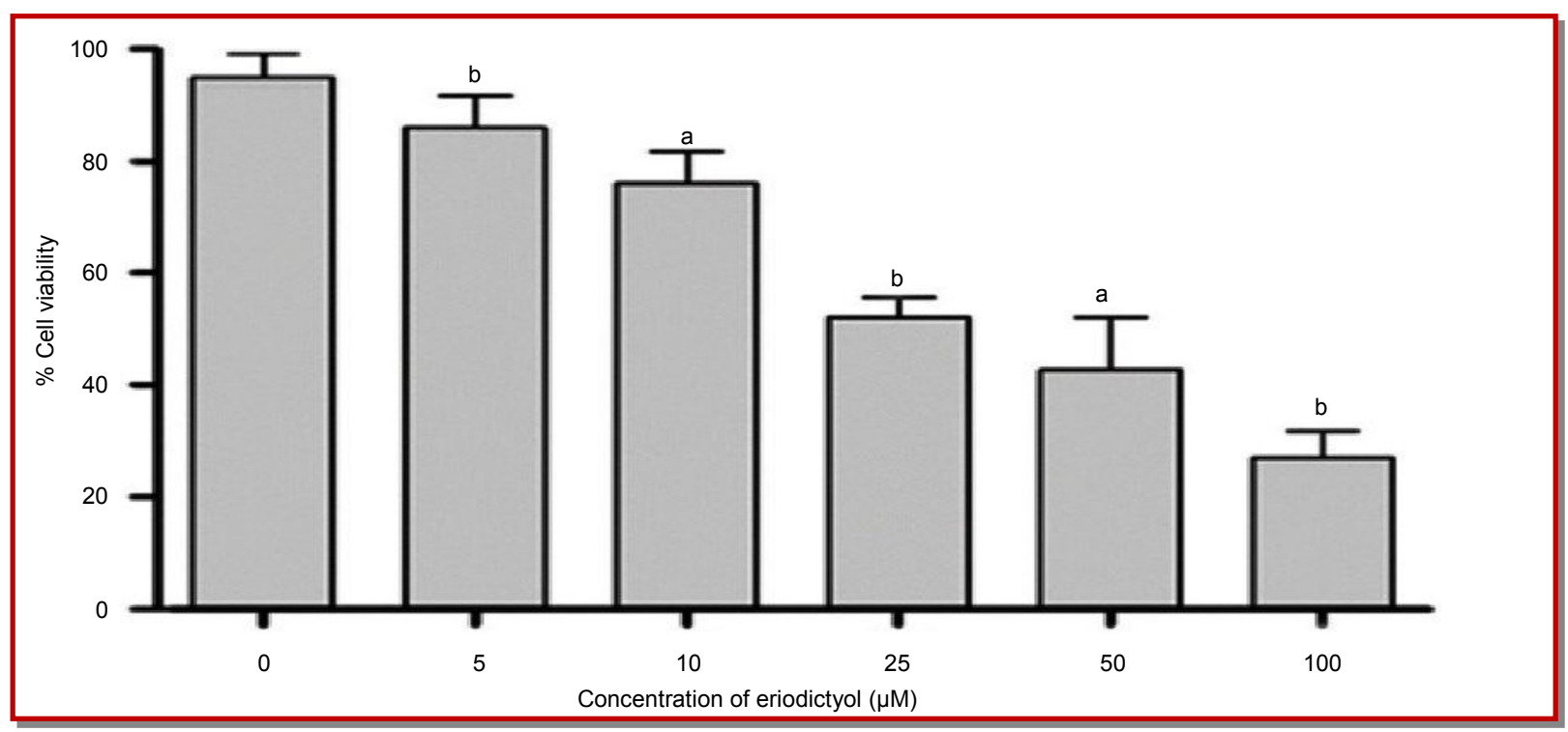

Figure 2: Cytotoxic effect of eriodictyol in human liver cancer cells (Hep-G2). Data are shown as mean \pm SD of three independent experiments. ${ }^{\mathrm{a}} \mathrm{p}<0.05,{ }^{\mathrm{b}} \mathrm{p}<0.01$, vs $0 \mu \mathrm{M}$ (control) 


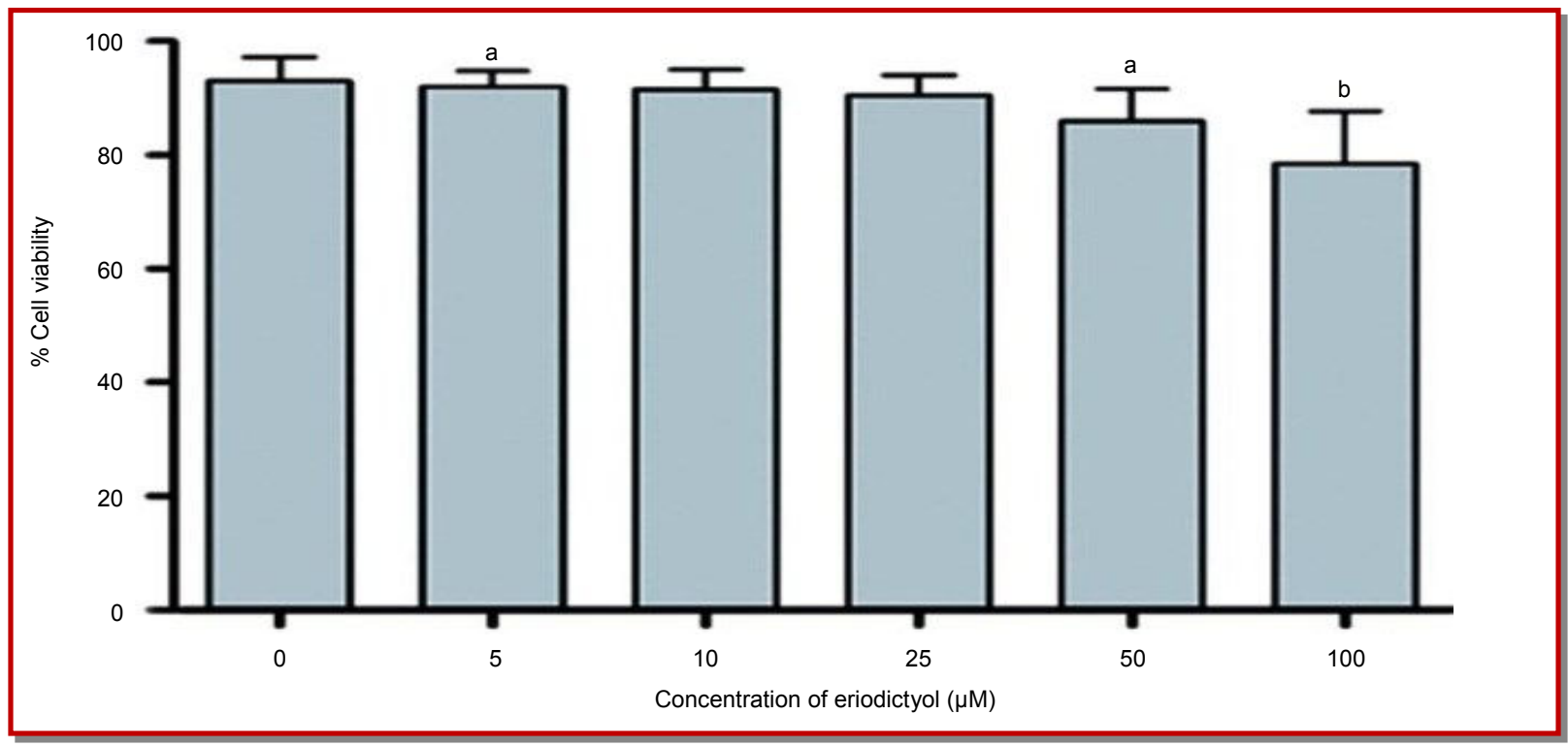

Figure 3: Cytotoxic effect of eriodictyol in AML12 normal liver hepatocyte cell line. Data are shown as mean \pm SD of three independent experiments. ap $<0.05$, bp $<0.01$, vs $0 \mu \mathrm{M}$ (control). The normal cells showed less susceptibility towards eriodictyol as compared to the cancer cells

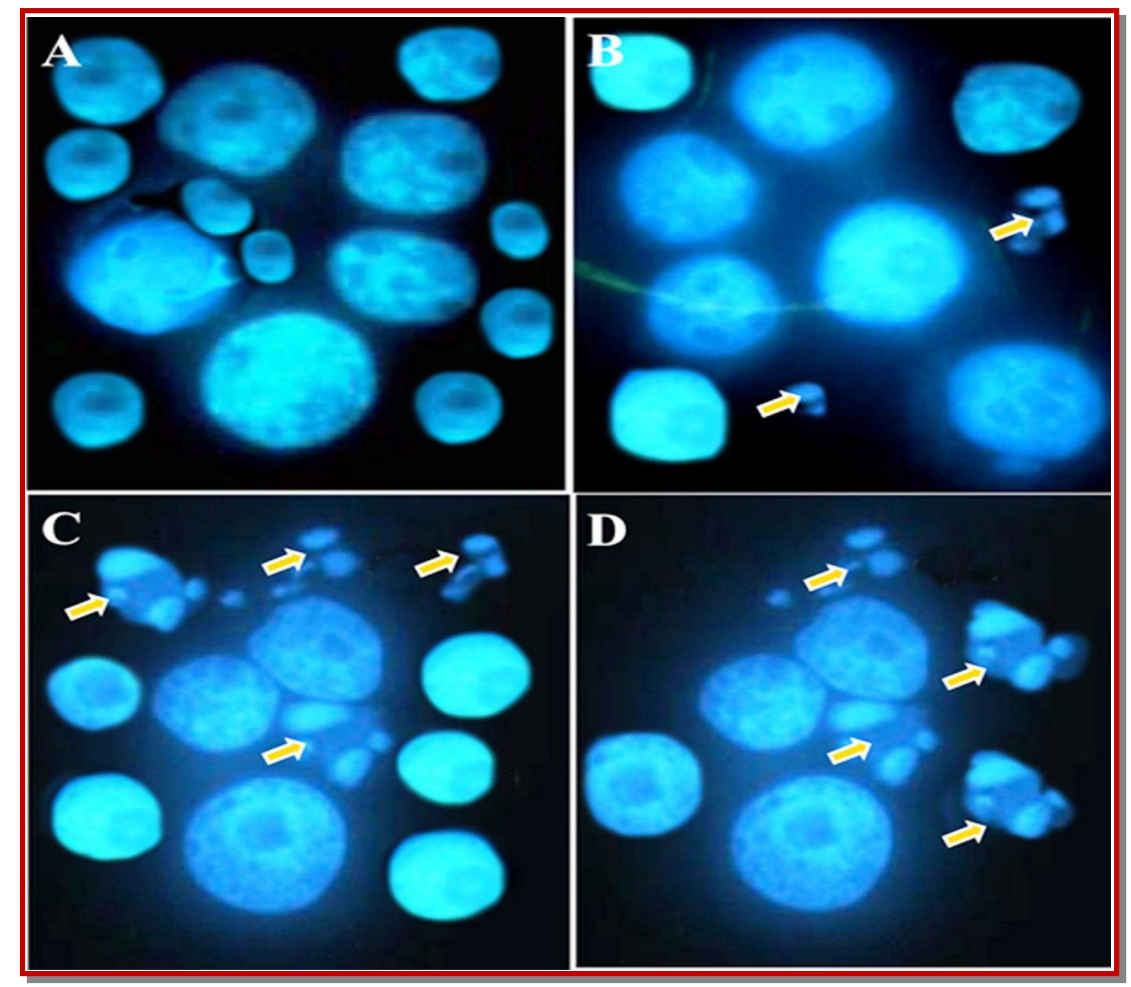

Figure 4: Fluorescence microscopic images of Hep-G2 cancer cells after treatment with 0 (A), 10 (B), 50 (C) and 100 (D) $\mu \mathrm{M}$ eriodictyol for 48 hours. The cells were stained with DAPI. Untreated cells (A) showed normal morphology while as treated cells showed signs of extensive apoptosis including chromatin condensation, nuclear fragmentation etc

This was accompanied by a corresponding decrease in the S-phase cells.

\section{Effect of eriodictyol on apoptosis-related protein expressions}

The current study also examined the effect of eriodictyol on the expression levels of various apoptosis -related proteins including Bax, PARP, Bcl-2 etc using western blot. The results of this assay are shown in Figure 7 and indicate that while as different concentrations of eriodictyol led to the up-regulation of Bax and PARP, it simultaneously also led to the down- 

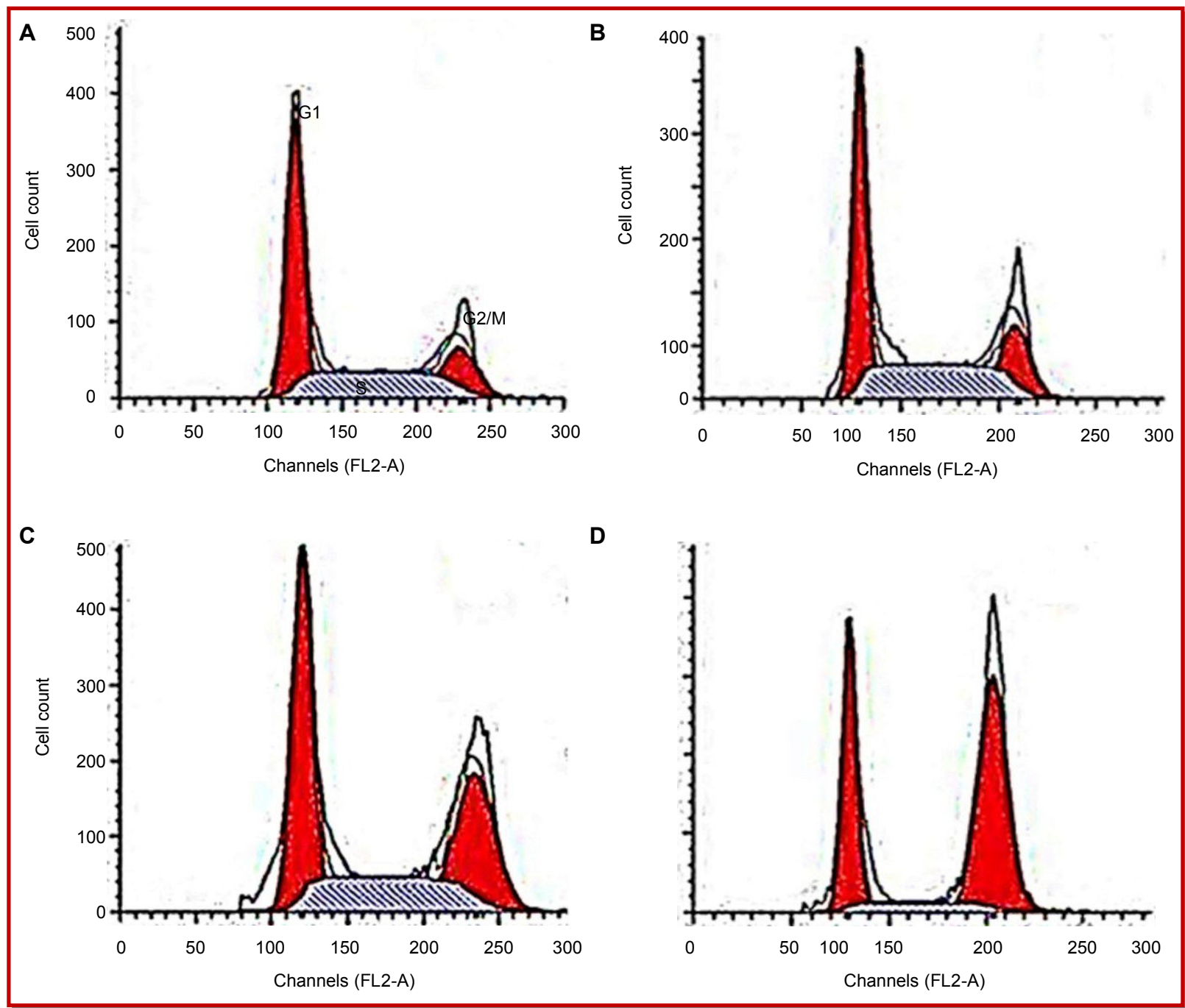

Figure 5: Eriodictyol induced G2/M phase cell cycle arrest in Hep-G2 liver cancer cells. The cells were treated with 0 (A), 10 (B), 50 (C) and 100 (D) $\mu \mathrm{M}$ eriodictyol for 48 hours and then analyzed by flow cytometry

regulation of $\mathrm{Bcl}-2$ protein. The expression level of cytochrome c was also decreased.

\section{Discussion}

The present study indicates that eriodictyol at almost all doses selectively targets cancer cells without causing too much damage to AML12 normal liver hepatocyte cells. Further, fluorescence microscopy indicated that eriodictyol led to the induction of apoptosis in these cells as the eriodictyol treatment of Hep-G2 cells showed chromatin condensation, nuclear fragmentation and cellular shrinkage. The untreated cells showed normal morphology. Flow cytometric investigation using propidium iodide indicated that eriodictyol led to G2/M phase cell cycle arrest as the fraction of cells in G2/M phase increased significantly with a correspondding decrease in $S$ phase cells. Western blotting assay exhibited that eriodictyol resulted in upregulation of
Bax and PARP and simultaneous downregulation of $\mathrm{Bcl}$ -2 protein. The expression level of cytochrome c was also decreased.

Natural products from plants especially flavonoids exhibit potential anti-cancer activities against a range of cancer cells. Natural products exert their anticancer effects via a variety of pathway including disturbing the normal cell cycle phase distribution, inducing apoptosis through both intrinsic and extrinsic pathways, upregulating and down-regulating various apoptosis related proteins expressions (Pietenpol and Stewart, 2002; Flatt and Pietenpol, 2000; Pfeuty et al., 2008). Apoptosis is a programmed cell death categorized by chromatin condensation, DNA fragmentation, cell shrinkage, membrane blebbing and apoptotic body formation. Apoptosis plays key role in the development of most of the malignancies. Most of the tissues that grow cancer specify a reduced rate of apoptosis process. Any disturbances in the process of apoptosis leads to 


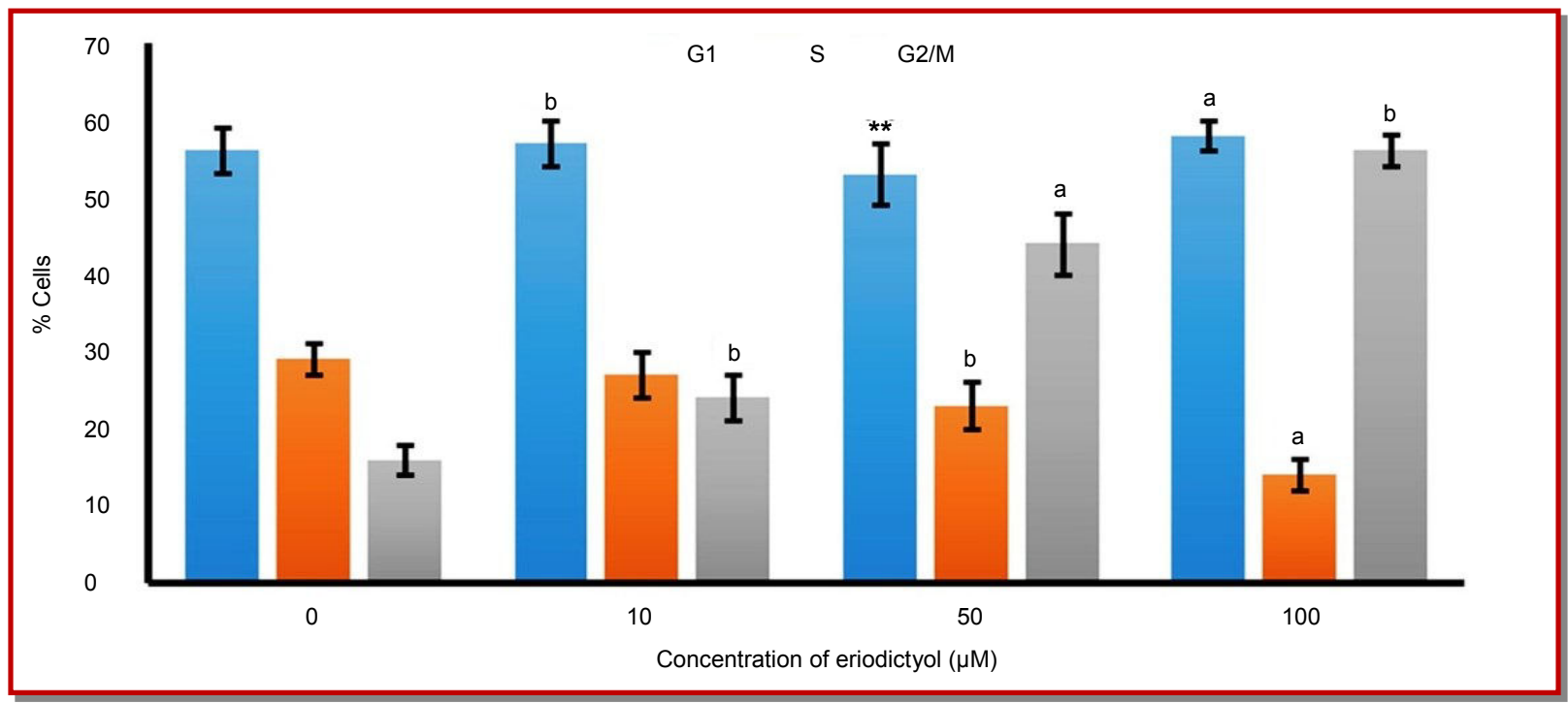

Figure 6: Graphical representation of the increase in the G2/M phase cells (G2/M arrest) after the Hep-G2 cells were treated with $0,10,50$ and $100 \mu \mathrm{M}$ eriodictyol for 48 hours. The results are mean \pm SEM and mean values of three independent experiments. ${ }^{\mathrm{a}} \mathrm{p}<0.05,{ }^{\mathrm{b}} \mathrm{p}<0.01$ versus the $0 \mu \mathrm{M}$ (untreated control)

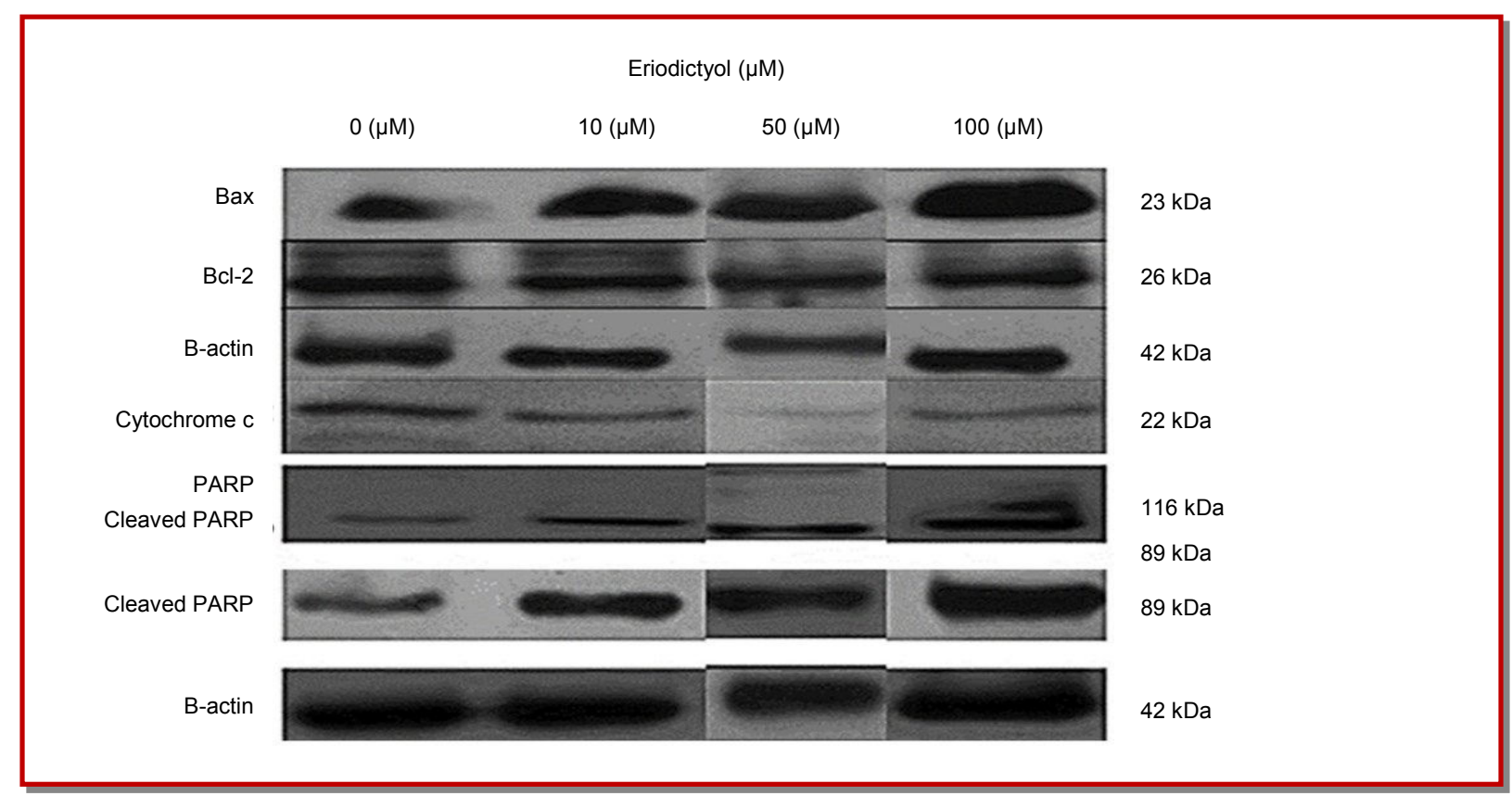

Figure 7: Effect of eriodictyol on the expression levels of various apoptosis-related proteins in Hep-G2 liver cancer cells. The expression levels of these proteins were detected by Western blot followed by treatment of cells with $0,10,50$ and $100 \mu \mathrm{M}$ eriodictyol for 48 hours

several disorders including tumor development (Qazzaz et al., 2015; George and Abrahamse, 2015).

\section{Conclusion}

Eriodictyol exhibited potent, dose-dependent and selective anticancer effects in Hep-G2 human hepatocellular carcinoma cells by inducing apoptosis, G2/M cell cycle arrest and up-regulation of Bax and
PARP and simultaneous down-regulation of Bcl-2 protein. Since, the molecule shows selective anticancer effect, it can be further developed as a potential anticancer drug candidate.

\section{Conflict of Interest}

The authors declare that there is no conflict of interest to reveal. 


\section{References}

Amin A, Hamza AA, Bajbouj K, Ashraf SS, Daoud S. Saffron: A potential candidate for a novel anticancer drug against hepatocellular carcinoma. Hepatology. 2011; 54: 857-67.

Clavin M, Gorzalczany S, Macho A, Muñoz E, Ferraro G, Acevedo C, Martino V. Anti-inflammatory activity of flavonoids from Eupatorium arnottianum. J Ethnopharmacol. 2007; 112: $585-89$.

Fabregat I. Dysregulation of apoptosis in hepatocellular carcinoma cells. World J Gastroenterol. 2009; 15: 513-20.

Flatt PM, Pietenpol JA. Mechanisms of cell-cycle checkpoints: At the cross-roads of carcinogenesis and drug discovery. Drug Metab Rev. 2000; 32: 283-305.

George BP, Abrahamse H. A review on novel breast cancer therapies: Photodynamic therapy and plant derived agent induced cell death mechanisms. Anticancer Agents Med Chem. 2015.

Havsteen B. Flavonoids, a class of natural products of high pharmacological potency. Biochem Pharmacol. 1983; 32; 1141 -48 .

Jemal A, Bray F, Center MM, Ferlay J, Ward E, Forman D. Global cancer statistics. CA Cancer J Clin. 2011; 61: 69-90.
Ley JP, Krammer G, Reinders G, Gatfield IL, Bertram HJ. Evaluation of bitter masking flavanones from Herba Santa (Eriodictyon californicum (H. and A.) Torr., Hydrophyllaceae). J Agric Food Chem. 2005; 53: 6061-66.

Ngandeu F, Bezabih M, Ngamga D, Tchinda AT, Ngadjui BT, Abegaz BM, Dufat H, Tillequin F. Rotenoid derivatives and other constituents of the twigs of Millettia duchesnei. Phytochemistry 2008; 69: 258-63.

Pfeuty B, David-Pfeuty T, Kaneko K. Underlying principles of cell fate determination during G1 phase of the mammalian cell cycle. Cell Cycle. 2008; 7: 3246-57.

Pietenpol JA, Stewart ZA. Cell cycle checkpoint signaling: Cell cycle arrest versus apoptosis. Toxicology 2002; 181-182: 47581.

Qazzaz ME, Raja VJ, Lim KH, Kam TS, Lee JB, Gershkovich P, Bradshaw TD. In vitro anticancer properties and biological evaluation of novel natural alkaloid jerantinine $b$. Cancer Lett. 2015; 370: 185-97.

Tabone M, Pellicano R. Prevention of intrahepatic hepatocarcinoma recurrence in patients with viral cirrhosis: Two potential options. Minerva Gastroenterol Dietol. 2006; 52: 4752. 


\section{Your feedback about this paper}

1. Number of times you have read this paper 0

2. Quality of paper Click

3. Your comments 